\title{
Distinguishing between isthmic thyroglossal duct cyst and goitre on nuclear thyroid scan: A case report
}

\author{
Yetunde Ajoke Onimode, Segun Ayodeji Ogunkeyede, Peter Afolami Olanrewaju \\ Onimode YA, Ogunkeyede SA, Afolami P. Distinguishing between isthmic thyroglossal duct cyst and goitre on nuclear thyroid scan: A case \\ report. Malays Fam Physician. 2021;16(3);108-111. https://doi.org/10.51866/cr1230
}

\section{Keywords:}

Thyroglossal cyst, thyroid

dysgenesis, goitre,

radionuclide imaging,

ultrasonography, child,

preschool

\section{Authors:}

Segun Ayodeji Ogunkeyede

(Corresponding author)

$M B C H B$, FWACS, FMCORL

Department of Otorhinolaryngology

College of Medicine, University of

Ibadan, Ibadan, Oyo State, Nigeria

Department of Otorhinolaryngology University College Hospital, Ibadan

Oyo State, Nigeria

Email: segunkeyede@yahoo.com

\section{Yetunde Ajoke Onimode} MBBS, FCNP(SA)

Nuclear Medicine Unit, Department of Radiation Oncology, College of Medicine, University of Ibadan Ibadan, Oyo State, Nigeria

Department of Nuclear Medicine, University College Hospital, Ibadan, Oyo State, Nigeria

\section{Peter Afolami Olanrewaju} MBBS

Department of Nuclear Medicine, University College Hospital, Ibadan, Oyo State, Nigeria

\begin{abstract}
Thyroglossal duct cysts, which are the most frequently encountered congenital cervical anomalies in children, occur due to embryologic remnants of the thyroglossal duct. Although diagnosis may be challenging, clinicians can be aided by imaging and fine-needle aspiration biopsies. We describe the clinical management of a two-year-old boy with a thyroglossal duct cyst mimicking a goitre on a pertechnetate thyroid scan.
\end{abstract}

\section{Introduction}

The thyroid gland develops between the fourth and eighth weeks of intrauterine life. The anlage descends from the foramen caecum at the base of the tongue, through the infra-hyoid visceral space and to the anterior neck. The thyroglossal duct connects the origin and final site of the anlage. This duct should involute at approximately the tenth week of life. However, it may persist as a thyroglossal duct cyst (TGDC). ${ }^{1}$

TGDCs are commonly encountered in children, with $50 \%$ of children presenting TGDCs in the first decade of life. ${ }^{2}$ TGDCs mostly present as a neck swelling that is mobile with tongue protrusion. It may also contain ectopic thyroid tissue (1.5-62\%). ${ }^{3}$ Clinical features are important in making a diagnosis; however, imaging confirms the diagnosis, localises the thyroid gland and helps in decision making. ${ }^{4}$ Ultrasonography (USS) is an important initial imaging technique for TGDC, especially in children where radiation exposure must be minimal. ${ }^{5}$ Since 2006, pertechnetate thyroid scan (PTS) has been available at this facility and incorporated into clinical management. The latter is especially useful in localising thyroid ectopia. This article serves to illustrate the presentation and use of imaging studies to solve the diagnostic dilemma of a TGDC in the isthmus of the thyroid that simulated a goitre.

\section{Case presentation}

The patient was a two-year-old boy with asymptomatic, progressive midline anterior neck swelling referred for a PTS. He was referred from a secondary health facility due to the diagnostic dilemma in differentiating a suspected TGDC from an enlarged thyroid gland. The PTS scan aimed to determine whether this was the only thyroid gland in the patient since the cystic lesion was within the thyroid gland and the possibility to remove the entire diseased thyroid gland along with the cyst was high based on the preoperative assessment. Thus, the decision to search for ectopic and functional thyroid tissue is important before surgical care.

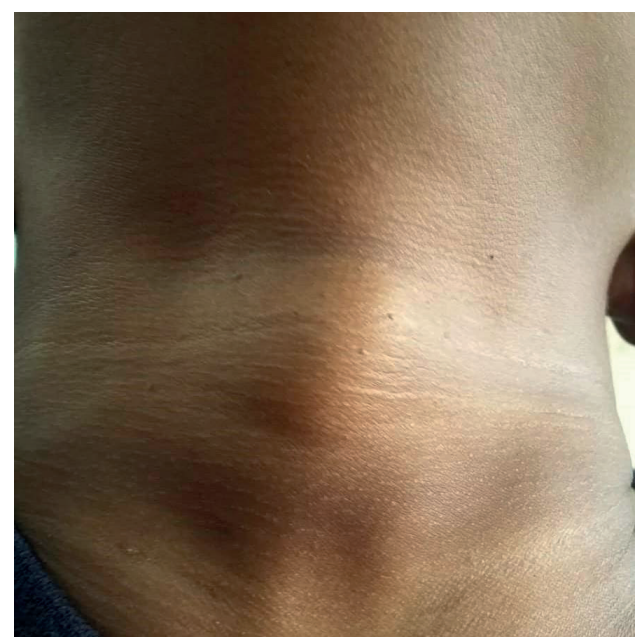

Figure 1. Anterior neck swelling observed at the patient's presentation for the scan.

On clinical examination, the patient had an anterior midline neck mass that moved more prominently with deglutition and not with tongue protrusion. It measured approximately 
$2 \times 1 \mathrm{~cm}$, with no differential warmth or tenderness. The swelling was soft to firm, attached to underlying structures and the overlying skin appeared normal (Figure 1). Fine-needle aspiration cytology (FNAC) was suggestive of a benign lesion.

A PTS showed a focal area of increased uptake in the anterior neck corresponding to both the neck swelling and thyroid gland, thereby making the distinction between the TGDC and goitre difficult. Uptake was uniform but lower than that of the salivary glands and slightly higher than background activity. No evidence of ectopic thyroid tissue was observed in an expanded field of scan (head to abdomen), thus excluding the likelihood of ectopic thyroid tissue (Figure 2).

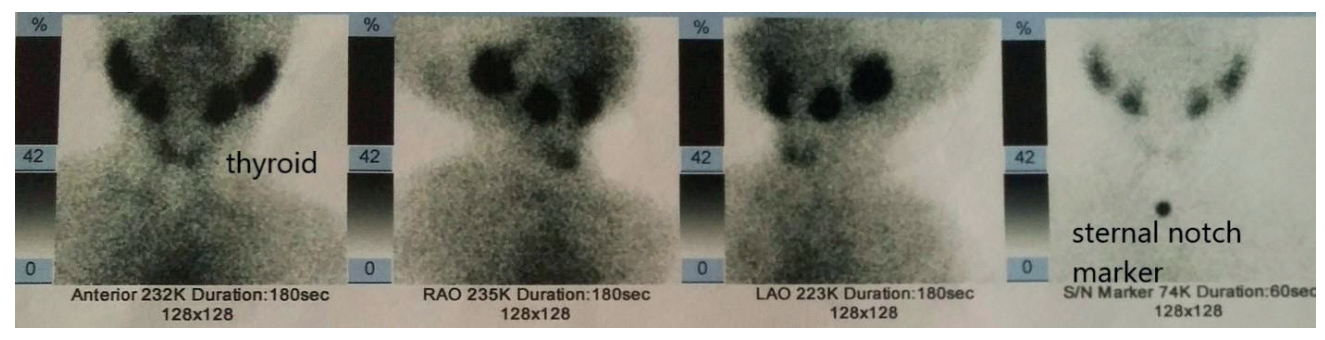

Figure 2. Pertechnetate thyroid scan showing anterior, right and left anterior oblique views as well as the sternal notch marker.

Subsequently, high-definition thyroid USS showed well-delineated normal thyroid tissue in the anatomical position as well as its size, outline and echogenicity along with a coexisting ovalshaped cystic mass of mixed intensity in the right para-median region. The cystic mass measured $14 \times 10 \times 15 \mathrm{~mm}$, had a volume of $1.2 \mathrm{ml}$ in the anterior neck, was attached to the thyroid isthmus and displaced the right thyroid lobe inferiorly, and was of normal colour flow Doppler interrogation, thereby confirming the potential for a TGDC.

Thereafter, the patient received a Sistrunk procedure. At surgery, there was an independent, tough, intact membrane containing serous fluid at the isthmus of the thyroid displacing the right lobe inferolaterally (Figure 3). It measured $24 \times$ $2 \mathrm{~mm}$ and there were no enlarged lymph nodes in the surrounding tissues. The histological report confirmed a TGDC. The patient was discharged on the second postoperative day without any complications. At the follow-up clinic, a postoperative thyroid function test was within normal limits.

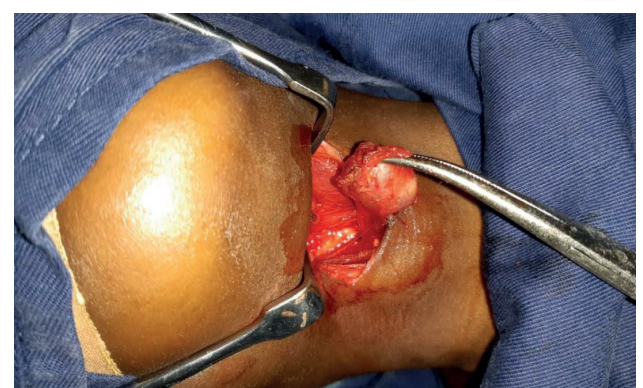

Figure 3. Intraoperative appearance of the isthmic thyroglossal duct cyst.

\section{Discussion}

In this case, the clinical presentation was that of an intra-thyroid benign cystic lesion with no cervical lymphadenopathy. Although TGDC is rarely associated with malignancy, papillary thyroid and squamous cell carcinoma have been reported in approximately $1 \%$ of patients with TGDCs. ${ }^{6}$ In this case, FNAC was suggestive of a benign lesion. In the management of TGDC, FNAC is reported as being safe and cost-effective in differentiating benign from malignant lesions. $^{7}$

In the process of making a correct diagnosis of suspected TGDC, one must ascertain the presence of the thyroid gland and ensure that the only thyroid tissue is not within the cyst to be removed. This would prevent one from unnecessarily subjecting a child to life-long thyroid hormone replacement therapy due to iatrogenic hypothyroidism. 8 Radiological and nuclear thyroid imaging localise eutopic and ectopic thyroid tissue, thereby complementing each other in clinical diagnosis. In this case, PTS helped to detect viable thyroid glands and the TGDC. The subsequent distinction between the TGDC and goitre was difficult since the increased uptake on PTS corresponded to both visible neck swelling and the thyroid gland. Thus, differential diagnoses included ectopic thyroid, TGDC, or TGDC with viable thyroid tissue. The suboptimal uptake of radioactivity by the neck mass further supported the latter differential. 
Clinical challenges experienced in the management of this patient were resolved by the complementary imaging of PTS and USS. Neck USS showed a complex relationship of the TGDC and adjacent normal thyroid tissue, which is responsible for the superimposition of focal cervical uptake on PTS. This arrangement explains the nonmovement of the cyst with tongue protrusion. Although TGDCs are typically located in the infra-hyoid area, other presentations include intra-laryngeal extension, intra-lingual cyst and lateral neck swelling. ${ }^{2}$

In thyroid ectopia, the entirety or part of the thyroid gland may be located in unexpected sites other than the anterior neck, which is considered a form of thyroid dysgenesis. ${ }^{1}$ In this case, thyroid ectopia was excluded via additional nuclear imaging from the floor of the mouth to the supra-pubic region, with no ectopic thyroid being detected. The common locations of ectopia include the base of the tongue, trachea, submandibular, lateral neck and palatine tonsils, heart, thymus, oesophagus, stomach, duodenum, gallbladder and adrenals. ${ }^{9}$

Although isthmic TGDCs are rare, intrathyroidal cysts have been reported. ${ }^{10}$ To our knowledge, this instance is an exceptionally rare case report of intra-thyroidal TGDC in Nigeria. In the present case, we did not find the thyroglossal duct tract. Nevertheless, the patient had an isthmusectomy and Sistrunk's procedure to prevent the recurrence of the TGDC.

\section{Conclusion}

The clinical and radiological features of TGDCs are important for diagnosis. However, complementary imaging studies are essential for intra-thyroid TGDCs. This report adds to the published literature on cases of TGDCs.

\section{Acknowledgements}

The authors thank Dr G.I. Ogbole for facilitating the neck ultrasound scan for this patient. Author YAO acknowledges support from the Consortium for Advanced Research Training in Africa (CARTA).

\section{Conflicts of interest}

The authors have no conflicts of interest to declare.

\section{Patients' consent for the use of images and content for publication}

Patient's caregiver provided written informed consent for use of images as well as consent for publication.

\section{What is new in this case report compared to the previous literature?}

- This case report provides additional evidence to the literature regarding intra-thyroid thyroglossal duct cyts.

\section{What is the implication to patients?}

Clinicians managing patients with a suspicion of thyroglossal duct cyst would keep in mind the possibility, though rare, of its being intrathyroid.

\section{References}

1. Nilsson M, Fagman H. Development of the thyroid gland [Internet]. Vol. 144, Development (Cambridge). Company of Biologists Ltd; 2017 [cited 2020 Mar 18]. p. 2123-40. Available from: http://www.ncbi. nlm.nih.gov/pubmed/28634271

2. Zander DA, Smoker WRK. Imaging of ectopic thyroid tissue and thyroglossal duct cysts. Radiographics. 2014;34(1):37-50.
3. Rosai J, Tallini G. Rosai and Ackerman's Surgical Pathology 10e E-Book. In: Rosai J, editor. Rosai and Ackerman's Surgical Pathology 10e E-Book [Internet]. 10th ed. Edinburgh; New York: Mosby Inc.; 2011 [cited 2020 Mar 27]. p. 487-564. Available from: http://books.google.ch/ books?id=1CKX7aGBbUsC
4. Dedivitis RA, Camargo DL, Peixoto GL, Weissman L, Guimarães A V. Thyroglossal duct: A review of 55 cases. J Am Coll Surg. 2002;194(3):274-7.

5. Ahuja AT, King AD, Metreweli C. Sonographic evaluation of thyroglossal duct cysts in children. Clin Radiol. 2000;55(10):770-4. 
6. Rayess HM, Monk I, Svider PF, Gupta A, Raza SN, Lin HS. Thyroglossal Duct Cyst Carcinoma: A Systematic Review of Clinical Features and Outcomes. Otolaryngol Head Neck Surg. 2017;156 (5): 794-802.

7. Pietruszewska W, Wagrowska-Danilewicz M, Józefowicz-Korczyńska M. Papillary carcinoma in thyroglossal duct cyst with uninvolved thyroid. Case report and review of the literature. Arch Med Sci. 2014 1;10(5):1061-5.
8. Lilley JS, Lomenick JP. Delayed diagnosis of hypothyroidism following excision of a thyroglossal duct cyst. J Pediatr. 2013 Feb;162(2):427-8.

9. Noussios G, Anagnostis P, Goulis DG, Lappas D, Natsis K. Ectopic thyroid tissue: Anatomical, clinical, and surgical implications of a rare entity. Eur J Endocrinol. 2011;165(3):375-82.
10. Álvarez Garcia N, Burgués Prades P, González Martínez-Pardo N, Simón Portero S, Fernández Atuán R. The intra-thyroid thyroglossal cyst in the differential diagnosis of the solitary thyroid nodule: A presentation of 2 cases. An Pediatría (English Ed.) 2015 May 1;82(5):360-1. 